\title{
Visualizing Brooklyn: the Brooklyn Visual Heritage Website
}

\author{
Tula Giannini \\ Pratt Institute \\ 144 West $14^{\text {th }}$ Street, New York, NY 10011, USA \\ giannini@pratt.edu
}

\begin{abstract}
Digitized primary resources are foundational to creating historical visualizations that can bring new light to ways of envisioning history tied to cultural heritage. The digitization of materials represents but a first step in a complex process that makes digital materials accessible and usable. It is a process that extends beyond creating digital objects to one that connects the object to metadata, description, access and use while also considering institutional policies and perspectives, copyright and licensing, intended audiences, use of social media, and interaction and user needs across a range of constituencies from historians and scholars to educators and the general public. The Brooklyn Visual Heritage website (BVH) (http://brooklynvisualheritage.org) represents a new visual resource for cultural heritage.
\end{abstract}

Digital cultural heritage. Institutional collaboration. Libraries. Archives and museums. Creating heritage websites. LIS education for digital culture.

\section{INTRODUCTION}

The Brooklyn Visual Heritage website was created as part of Project CHART (Cultural Heritage, Access, Research and Technology, Tula Giannini, Project Director), a 3-year collaborative project (2010-2013) between Pratt School of Information and Library Science, and three of New York's leading cultural Institutions, the Brooklyn Historical Society (BHS), Brooklyn Museum (BM)and Brooklyn Public Library (BPL) with funding from the Institute of Museum and Library Services (IMLS), a federal agency of the US government, The project's team of museum, library and archives staff with Pratt faculty and students have worked together to digitize and provide access to museum collections that have not been previously available. Designed within the broad context of today's global information landscape, the site, which was launched November 2012 with ongoing usability testing in Pratt's Cultural Informatics Lab, already is providing free public access to this newly digitized corpus of thousands of $19^{\text {th }}$ and $20^{\text {th }}$ century historic photographs of Brooklyn. To meet the educational goals of Project CHART, Pratt developed an18-credit curriculum for a new Digital Management for Cultural Heritage program that prepares students for careers in libraries, archives and museums in the digital world.

This paper looks at the Brooklyn Visual Heritage website from institutional, educational and user perspectives. It draws upon quantitative and qualitative data collected during the course of this 3 -year project as well as data from three preceding IMLS grants to Pratt-SILS partnering with the BHS and BM from 2005 to present. (See figure 5.) Much of this data is contained in annual reports to the IMLS so that this paper is in essence a case study. Key questions considered are those concerning institutional collaboration, open source, open access technology and digital design, and developing a curriculum that prepares students to think creatively and digitally. With Project CHART now in its final year, we ask, how will the BVH website be sustainable; how will its collections continue to grow, and how will it become part of today's global landscape for digital cultural heritage (not digital dust) as exemplified by Europeana and the latest efforts in the US for developing the Digital Public Library of America? These projects bring to the fore the need to design digital resources using collaborative and sustainable models supporting open access and with the hope that this new digital resource is used innovatively to visualize Brooklyn history.

\section{THE BVH WEBSITE}

The website's home page links to several sections which act as the main site navigation. The home page features an image slider with rotating images below this, four thumbnails of the most viewed images appear with image mouse-over to view the title while clicking the image takes the user to that image page. A brief statement about the site 
appears under the most viewed section. The advanced search page offers field specific searching, filters, and Boolean searching. The collections page presents the image collections by institution displaying a representative image and collection description as well as external links to finding aids and other pertinent resources. Clicking on a collection name displays the thumbnails of all its images. The blog page presents the last six posts; the default blog page display from the Community theme is used. The about page provides background information on Project CHART, including links to project documentation such as the grant narrative, student practicum projects, and links to partner pages. Tech Info details the technical aspects of the project, such as hardware specifications and technical metadata, and provides a "behind-the-scenes" look at coordinating, managing, and sustaining a collaborative digital project. This page links to the project architecture document and the functional requirements documents describing the site's open source platform, Drupal. The resources page serves as a subject guide to help visitors further their Brooklyn history research. Sidebar blocks are persistent throughout the site. Image search is prominent at the top of the sidebar and is restricted to image content. The Advanced Search page presents additional search options. Image browse links to browse images by collections and by subjects, while follow us embeds twitter data for the BVH twitter account. "Twitter Pull" is one Drupal module that supports this functionality. The image gallery shows 12 images randomly selected from the database. Title metadata appears when hovering on an image while clicking an image takes the user to that specific image page.

\subsection{Metadata, description, access and use}

The two screen shots of image records below (Figures 2 and 3 ) show the site's metadata structure and field descriptors which include: title, creator, date, institution, collection, subject, description, medium, location, ID no. and rights. This last field is noteworthy as it indicates whether or not the image has copyright restriction, which is especially important to those wishing to use the image for new works. Clicking on "order this image" links to the order page of the institution holding the physical image while clicking on the subject and location fields search within the BVH site. Regardless of copyright status or whether or not an image will be used for educational or commercial purposes, fees are associated with high- resolution images based on each institution's fee schedule.

\subsection{New Partners and Purposes - Plans to Sustain and Grow the BVH Website}

When this 3-year IMLS project ends in summer 2013, we plan to continue to digitize and describe new images. Pratt student interns with funding from Pratt will carrying-out this work at BHS, BM and BPL. At the same time, we are broadening the project's focus for the purposes of: enhancing user experience and participation through the use of social media, developing educational programs that incorporate $\mathrm{BVH}$ resources for children and young adults, providing primary source materials for digital humanities scholars and historians, and introducing new courses for the digital management concentration that speak to faculty and student interests in research and projects. These initiatives as well as projects using mobile and web computing will connect Brooklyn communities, past and present to create new visualizations of Brooklyn history while informing its future. As part of our K-12 education initiatives with BHS and BPL, Pratt-SILS library media specialist faculty and students will use BVH resources for teaching and learning in NYC public schools to connect students to the rich cultural environments of these institutions.

\section{PEDAGOGY AND CURRICULUM FOR CULTURAL HERITAGE - REAL AND VIRTUAL}

Project CHART's new 18-credit curriculum, Digital Management for Cultural Heritage is designed to prepare Pratt-SILS graduates for careers in cultural heritage institutions. In the process of developing this program, our goal was to create a set of courses that responds to the challenges of today's digital revolution as it transforms our ways of doing and knowing and by extension, the need for users to inhabit simultaneously the real and virtual life of New York's cultural institutions. Representing a central concept of the program, it calls for reconciling traditional theory and practice for cultural heritage with digital media and emerging technology.

Pratt-SILS education is distinguished by a pedagogy that harmonizes philosophy, theory and practice with experiential learning and research. The integration of these elements makes up the rich fabric of a dynamic learning environment. SILS classrooms, designed as seminar labs, each with $15 \mathrm{Mac} / \mathrm{PC}$ computers and specialized software and equipment, support participatory and interactive learning through an iterative process that moves from lecture and discussion to application by which students apply what they have learned and work independently or in teams on projects. Our teaching labs (iLab, Cultural Informatics Lab and Digital Media Lab) are designed for faculty and student research in digital 
culture having equipment for creating and editing video, the Atiz book scanner for digitizing rare books and manuscripts and software for information design and user studies such as Morae and SPSS. Although most library and information science schools have embraced distance learning, Pratt has by contrast strengthened experiential and contextual learning. For example, the course, Museum and Library Research is taught on-site at the Metropolitan Museum of Art, Watson Library, Map Collections is taught in the Map Division of New York Public Library, 42nd Street and some 25 students per semester do internships in NYC cultural institutions. (See Figure 7 for a list of new courses created for the digital management program).

\section{DIGITIZATION MAKES REAL THE USE OF VIRTUAL COLLECTIONS}

Increasingly, libraries, archives and museums are creating digital resources drawn from their collection materials, exhibition catalogs, rare books and special collections to support not only individual scholars, but also, the work of the museum itself. With these new digital resources on the one hand and digital technologies for connecting art and information on the other, whether in the real or virtual museum, user experience becomes more meaningful and thoughtful. Digital information across all aspects of museum function now transforms how the museum experience is conceptualized while it redefines the user experience as participatory and interactive. In this framework of re-designing museums for the digital age, the work of information professionals moves from the siloed space of the library to a new team-based approach that works across institutional boundaries linking newly minted departments of digital media, digital asset management and e-publishing with traditional curatorial departments. As people spend more time in virtual life than real - digitization of collections across libraries, archives and museums is fast becoming a requirement of making useful and usable cultural heritage. Already with the BVH website, we see greater interest in the photographic collections of BHS, BM and BPL as well as greater appreciation and support for their meaning and value to the Brooklyn community and beyond. With more than 11,500 images digitized and accessible, BVH constitutes a major resource that conveys Brooklyn's history and importantly, visualizes the everyday life of the borough's diverse population from about 1850 to 1979 offering detailed views of neighborhoods from their architecture and public spaces to stores, houses and streets. Connecting these images with contemporary views of Brooklyn, from what was, to what is, users can create new narratives and visualizations of Brooklyn's history.

Project CHART Narrative by Tula Giannini (2010): http://www. pratt.edu/uploads/Narrative.

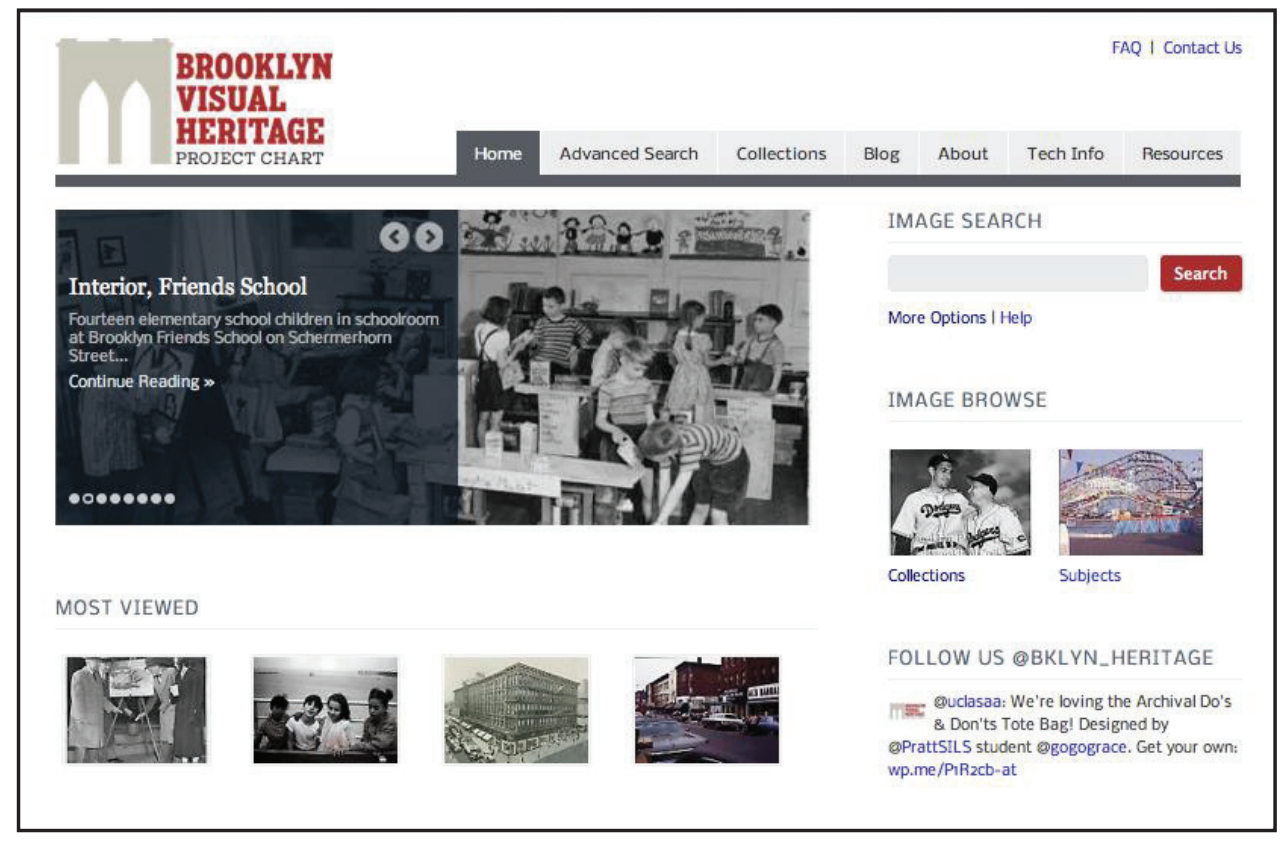

Figure 1: BVH Home page, top section - the BVH site is hosted by BPL 
DUMBO, BROOKLYN WATERFRONT PHOTOGRAPHS AND SLIDES
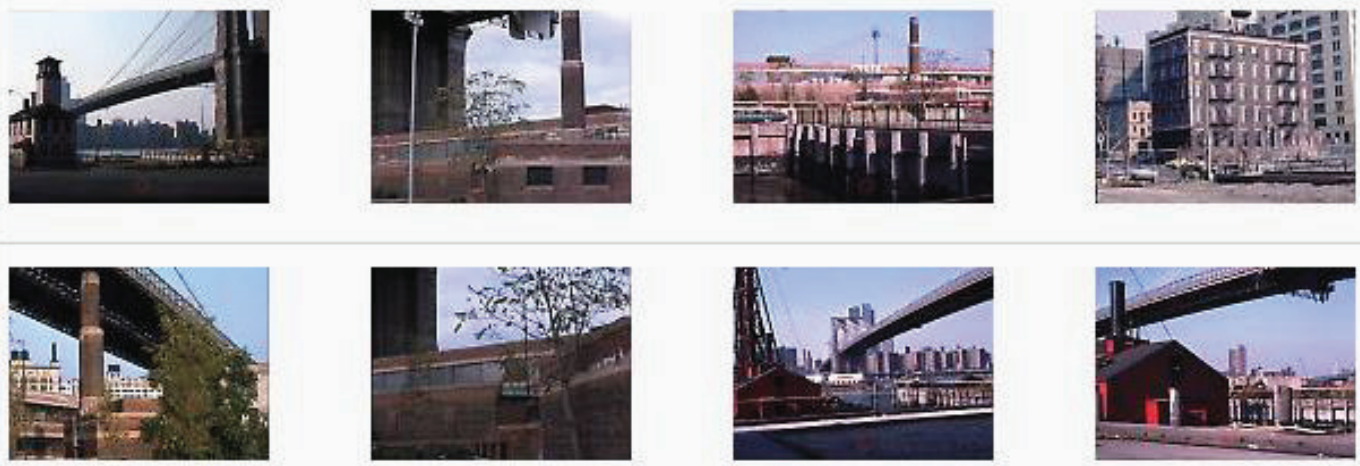

Figure 2: BVH Browse Collections feature

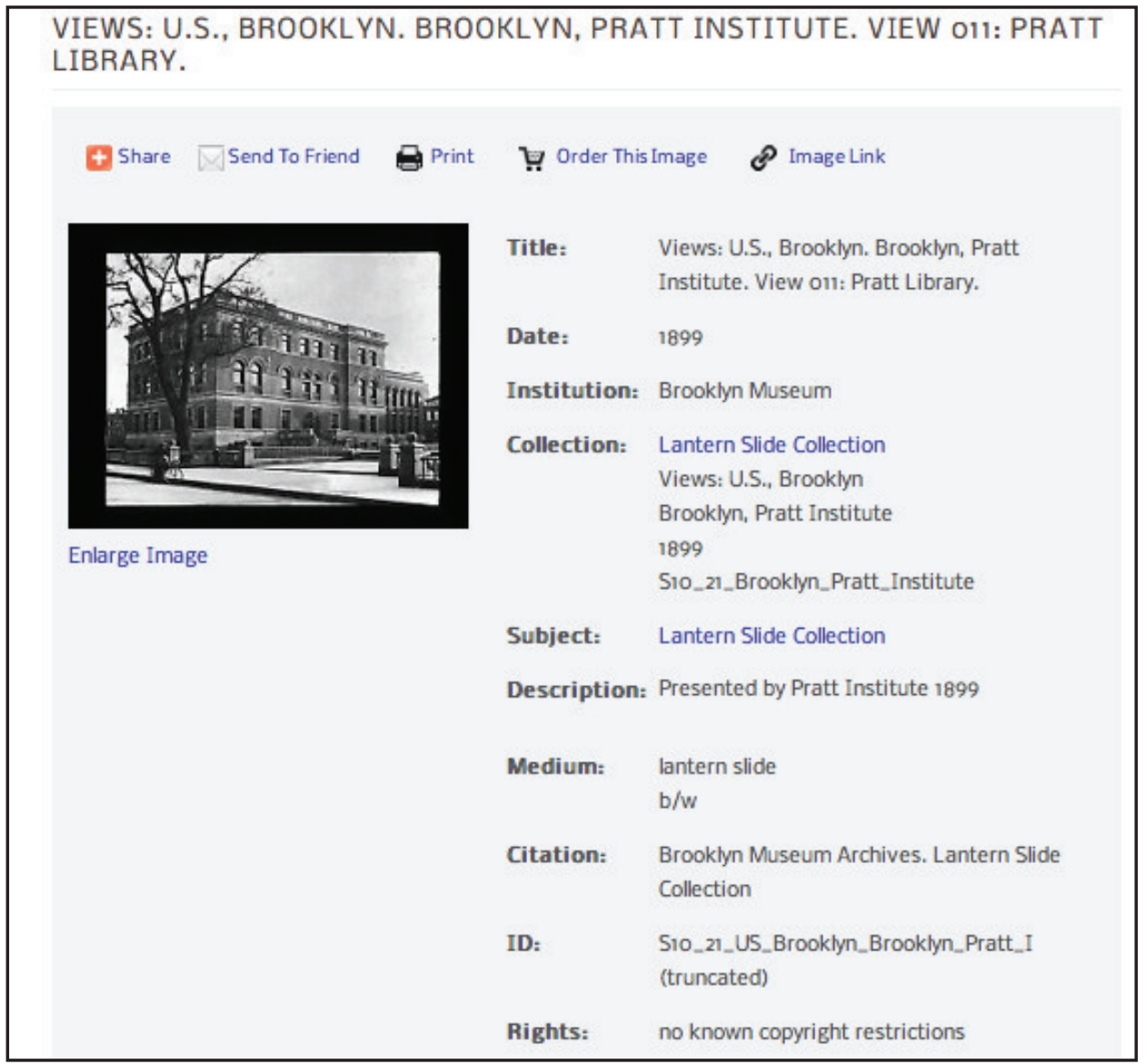

Figure 3: BVH image record of a work in public domain 


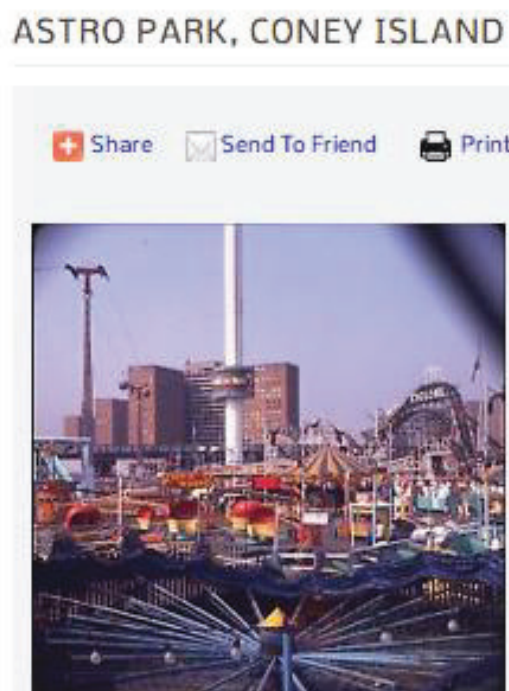

Enlarge Image

Why am I seeing a watermark?
ㅂ Order This Image $\quad$ Image Link

Title: Astro Park, Coney Island

Creator: Dreschmeyer, Otto

Date: $\quad 7 / 16 / 1968$

Institution: Brooklyn Historical Society

Collection: Otto Dreschmeyer Brooklyn slides

Subject: Amusement parks

Amusement rides

Buildings

Roller coasters

Description: View of Astroland's rides, including the Cyclone roller coaster and the Tilt-A-Whirl, at Coney Island. (Hot) [written on verso].

$\begin{array}{ll}\text { Medium: } & \text { Color slides } \\ \text { Location: } & \begin{array}{l}\text { Brooklyn (New York, N.Y.) } \\ \text { Coney Island (New York, N.Y.) }\end{array} \\ \text { ID: } & \text { V1988.12.48 } \\ \text { Rights: } & \text { RESTRICTED. }\end{array}$

Figure 4: BVH image record showing a work under copyright restriction 


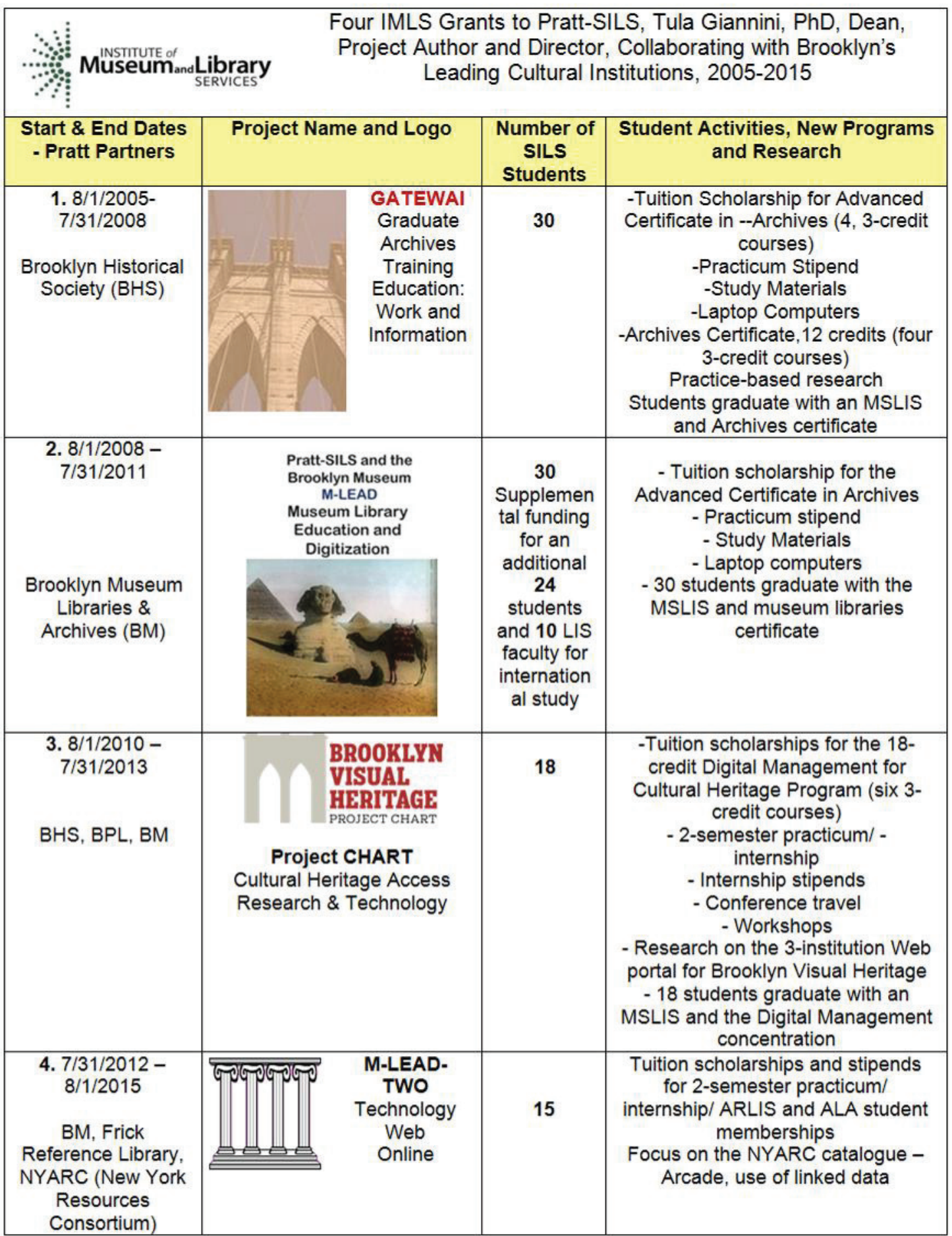

Figure 5: Chart detailing Pratt-SILS IMLS funded projects and partners 


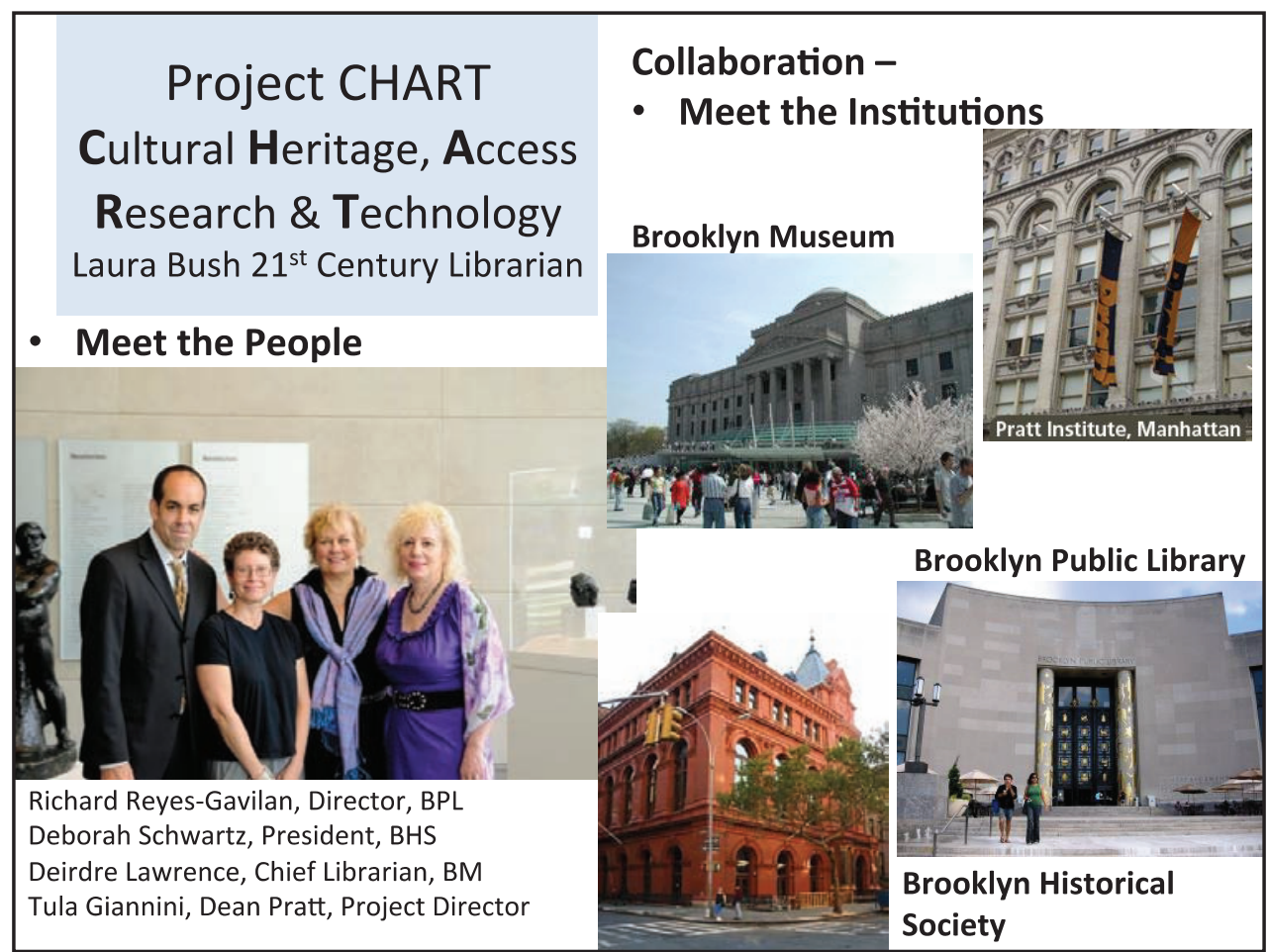

Figure 6: Project CHART collaborating institutions and project leaders (PowerPoint slide)

\section{Project疏ctivities庭}

PrPFANew

- Cultural[Heritage

- Education@Pratt-SIL通

Programming[for [Cultural[Heritage?

防tudents

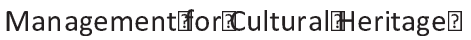

- Visual[Resources[Management?

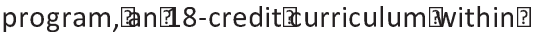

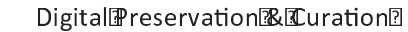

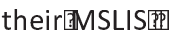

- Digital[EH umanities[?

- Digital[scholarship

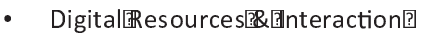

- Students

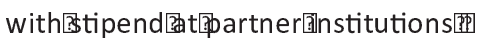

Information /isualization?

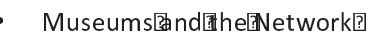

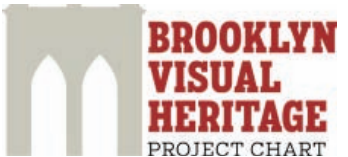

- Projects[ing

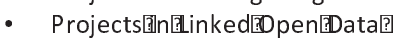

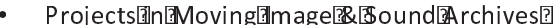

HERITAGE

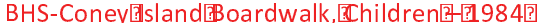

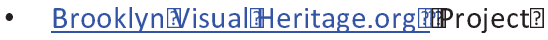

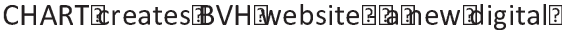

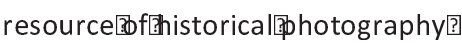
collections 通cross the 团hree

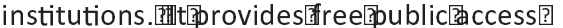

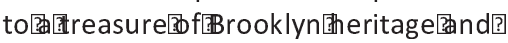

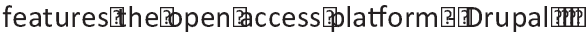

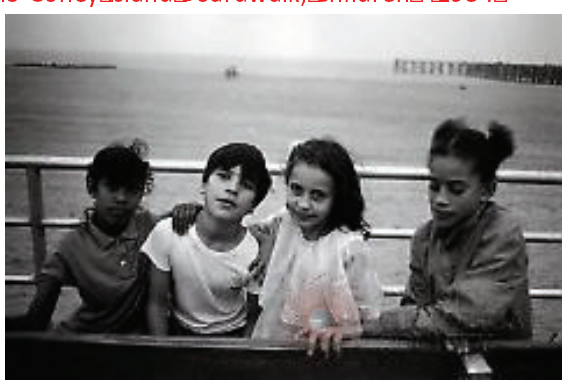

Figure 7: Summary of project activities with BVH image (PowerPoint slide) 


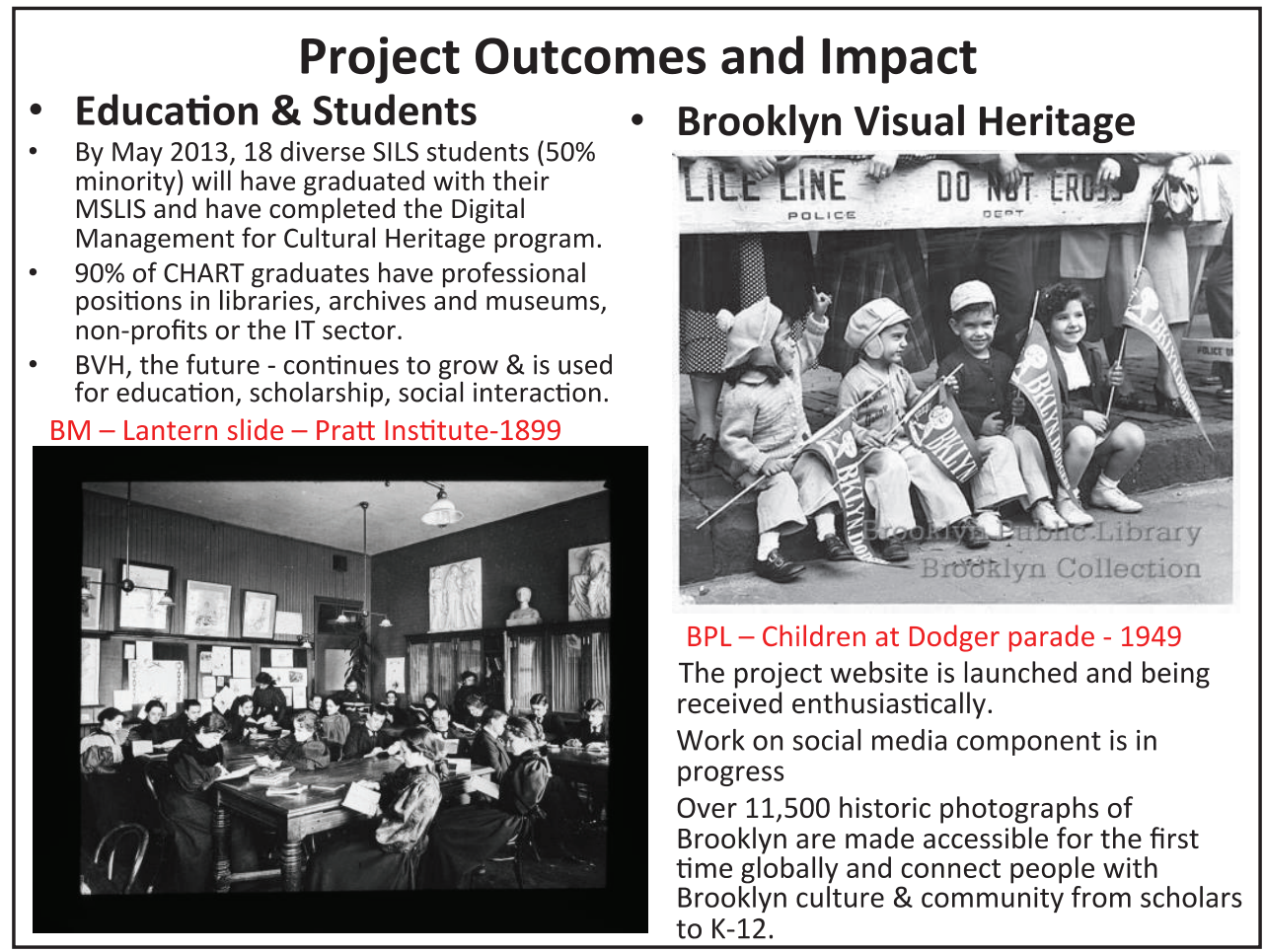

Figure 8: Project outcomes with BVH images (PowerPoint slide)

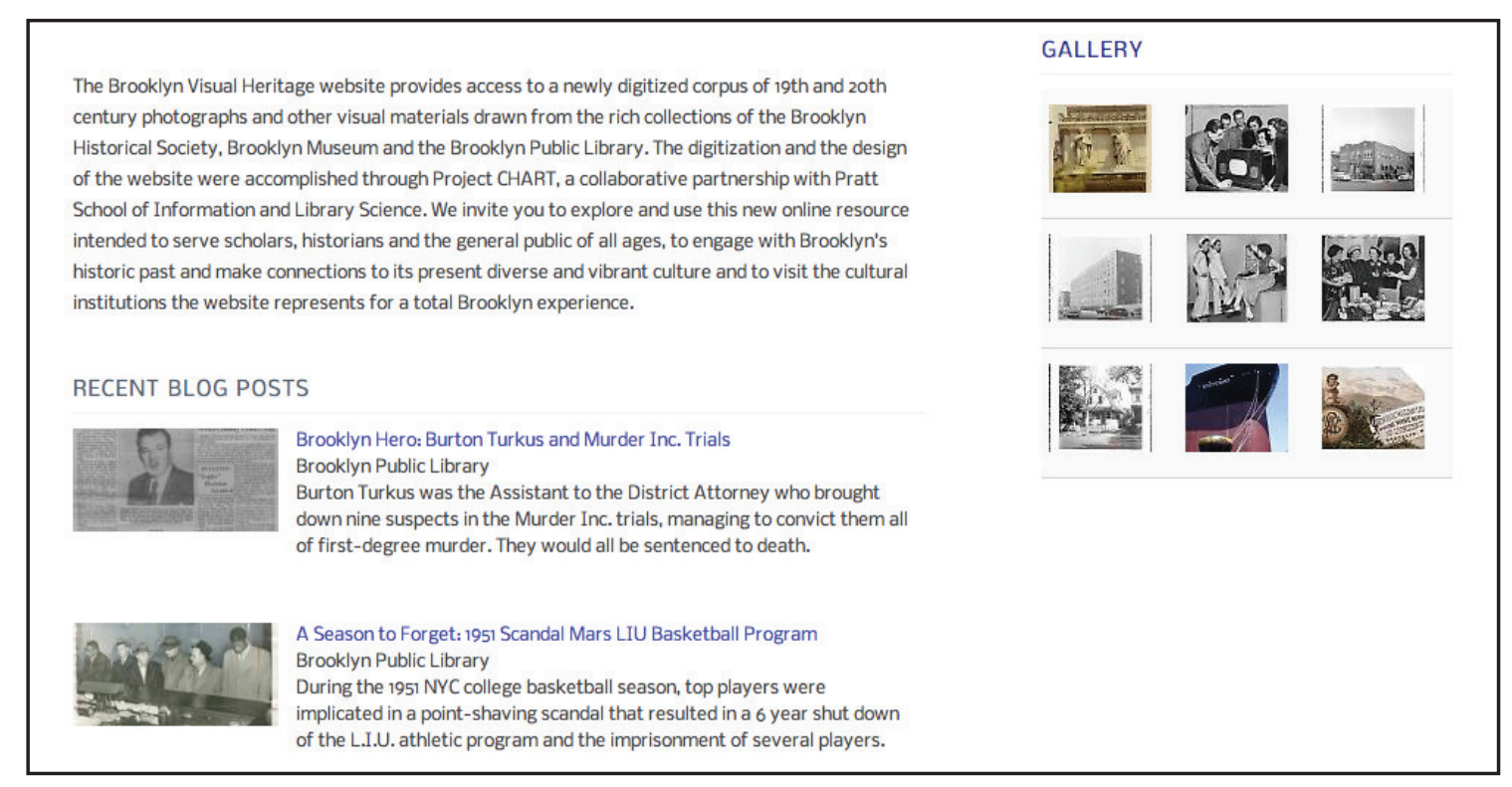

Figure 9: BVH Home page, center section features blogs and the gallery 